\title{
Induction of immune responses and safety profiles in rhesus macaques immunized with a DNA vaccine expressing human prostate specific antigen
}

\author{
J Joseph Kim ${ }^{1,2}$, Joo-Sung Yang ${ }^{2}$, Liesl K Nottingham², Waixing Tang ${ }^{3}$, Kesen Dang 2 , \\ Kelledy H Manson ${ }^{4}$, Michael S Wyand ${ }^{4}$, Darren M Wilson² and David B Weiner*,2,5 \\ ${ }^{1}$ Viral Genomix, Inc., Philadelphia, Pennsylvania, PA 19104, USA; ${ }^{2}$ Department of Pathology and Laboratory Medicine, \\ University of Pennsylvania, Philadelphia, Pennsylvania, PA 19104, USA; ${ }^{3}$ Institute of Human Gene Therapy, Philadelphia, \\ Pennsylvania, PA 19104, USA; ${ }^{4}$ Primedica Mason Labs, Worcester, Massachusetts, USA; ${ }^{5}$ The Wistar Institute, Philadelphia, \\ Pennsylvania, PA 19104, USA
}

Prostate specific antigen (PSA) is a widely used marker for prostate cancer, which is secreted by normal prostate cells at low levels, but is produced more substantially by cancer cells. We have previously reported on the use of a DNA vaccine construct that encodes for human PSA gene to elicit host immune responses against cells producing PSA. DNA immunization strategy delivers DNA constructs encoding for a specific immunogen into the host, who becomes the in vivo protein source for the production of antigen. This antigen then is the focus of the resulting immune response. In this study, we examine the induction of immune responses and safety profiles in rhesus macaques immunized with DNA-based PSA vaccine. We observed induction of PSA-specific humoral response as well as positive PSA-specific lymphoproliferative (LPA) response in the vaccinated macaques. We also observed that the stimulated $T$ cells from the PSAimmunized rhesus macaques produced higher levels of Th1 type cytokine IFN- $\gamma$ than the control vector immunized animals. On the other hand, DNA immunization did not result in any adverse effects in the immunized macaques, as indicated by complete blood counts, leukocyte differentials and hepatic and renal chemistries. The macaques appeared healthy, without any physical signs of toxicity throughout the observation period. In addition, we did not observe any adverse effect on the vaccination site. The apparent safety and immunogenecity of DNA immunization in this study suggest that further evaluation of this vaccination strategy is warranted. Oncogene (2001) 20, $4497-$ 4506 .

Keywords: prostate specific antigen; DNA vaccines; prostate cancer; immune responses; rhesus macaques

*Correspondence: DB Weiner, Department of Pathology and Laboratory Medicine, University of Pennsylvania, 505 StellarChance, 422 Curie Blvd., Philadelphia, PA 19104, USA;

E-mail: dbweiner@mail.med.upenn.edu

Received 23 January 2001; revised 9 April 2001; accepted 12 April 2001
Introduction

Prostate cancer is the most common malignancy in American men and is the second leading cause of cancer related death in the male population (Boring et al, 1994). It is estimated that 184500 men were diagnosed with prostate cancer and 39200 men died of the disease in 1998 in the United States (Garnick and Fair, 1998). Present treatment for prostate cancer includes radical prostectomy, radiation therapy or hormonal therapy. Even though traditional surgical androgen deprivation has been largely replaced by hormonal therapy, no systemic therapy has clearly improved the hormone refractory disease. Even early treatment through surgery or radiation therapy does not always achieve complete eradication of the tumor and can lead to unwanted side effects such as impotence and urinary incontinence (D'Amico et al., 1998; O'Donnell and Finan, 1989; Zagars and Pollack, 1995).

Prostate specific antigen (PSA) is a 240 amino acid member of the glandular kallikrein gene family (Wang et al., 1982; Watt et al., 1986). PSA is a serine protease secreted by both normal and transformed epithelial cells of the prostate gland (Wang et al., 1982). PSA can be detected in the sera of healthy males at low levels without clinical evidence of prostate cancer. However, PSA is secreted more substantially by cancer cells (Wang et al., 1982; Stenman et al., 1999). Since PSA expression appears to be limited to prostate cells, it is now the most widely used marker for prostate cancer (Godley, 1999; Labrie et al., 1992). Furthermore, the tissue specificity of PSA makes it a potential target for the development of immunotherapies against prostate cancer (Armbruster, 1993; Hodge et al., 1995). However, the lack of strong surface expressed PSA makes targeting these antigen expressing cells complex.

We have previously reported on the use of DNA immunization in mice to elicit host immune responses against cells producing PSA (Kim et al., 1998b). Specifically, a DNA vaccine construct which encodes for human PSA gene was cloned into expression vectors. Then the mice were immunized intramuscularly with these DNA vaccines and the in vivo immune responses were examined. Injection of the PSA plasmid 
induced a strong and persistent antibody response against PSA following immunization. In addition, DNA immunization induced significant PSA-specific $\mathrm{T}$ helper cell proliferative as well as $\mathrm{CD}^{+} \mathrm{T}$ cellrestricted cytotoxic $\mathrm{T}$ lymphocyte responses in mice. The CTL response allows for destruction of PSAexpressing cells without the requirement for strong surface expression. These results demonstrate the potential utility of targeting PSA as a testable immunotherapy against prostate cancer.

Important for the ultimate use of DNA vaccine technology in humans is that results originally observed in mouse systems translate to animal models more similar to the clinical setting. Previously, it has been reported that primates may have a limited ability to produce DNA vaccine-encoded proteins through direct genetic inoculation into muscle (Jiao et al., 1992). More specifically, it has been reported that DNA immunizations alone in primates induce weak immune response (Letvin et al., 1997). These observations suggest reduced immunogenecity of DNA vaccines in hon-human primates, potentially limiting their utility. Because of the high degree of similarity between the rhesus macaques and human prostate gland and PSA (94\%), the rhesus macaque model is well suited to accurately assess the effects of PSA vaccine.

In this study, we report on the first examination of immune responses and safety in rhesus macaques immunized with DNA-based PSA vaccine. We observed induction of PSA-specific immune responses in rhesus macaques without any signs of adverse reaction to the vaccination.

\section{Results}

\section{Vector construction and in vitro expression}

DNA vaccine constructs expressing human PSA (pCPSA) was cloned into an expression vector under control of a CMV promoter as previously described (MacGregor et al., 1998). The vector has a Kanamycin resistance gene as a selectable marker. Similar DNA backbones have been previously evaluated in hundreds of humans without any major side effect (MacGregor et al., 1998). To confirm the expression of pCPSA in a monkey cell line, we transfected COS cells in vitro using a method previously described. Three days following transfection, the transfected cells were stained with $\alpha$-PSA antibody and observed under microscope. As shown in Figure 1b, we observed an expression of PSA in COS cells transfected with pCPSA. Untransfected control cells did not show expression of PSA (Figure 1a).

\section{DNA immunization induces PSA-specific antibody responses in rhesus macaques}

We investigated whether the induction of PSA-specific immune responses observed in mice through DNA

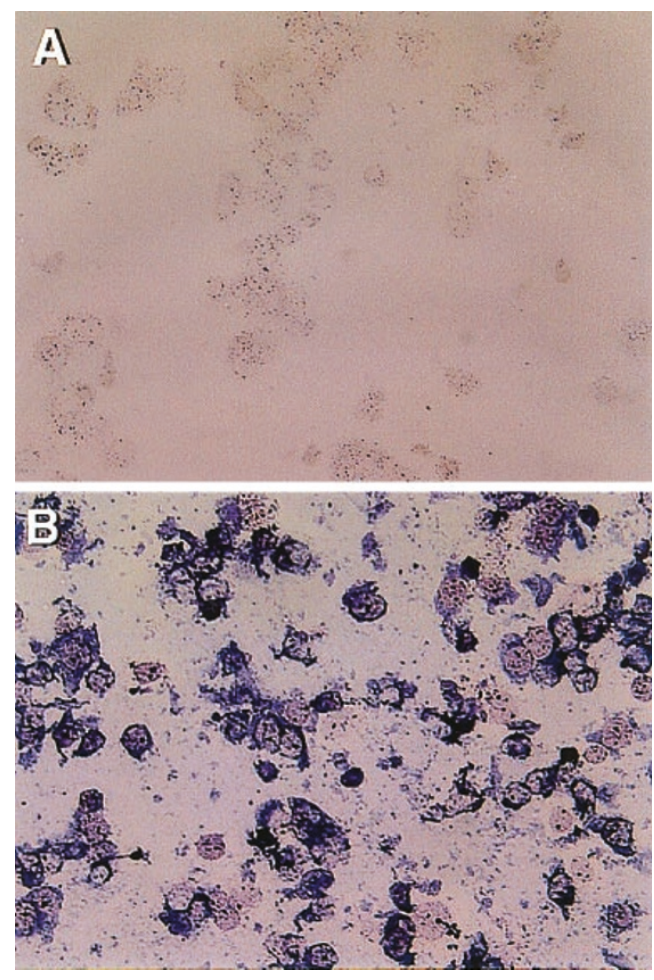

Figure 1 Construction and in vitro expression of pCPSA. The complete coding sequence of human PSA was cloned into a clinical expression vector under control of a CMV promoter and a Kanamycin resistance gene as a selectable marker. The proper expression of PSA protein was assayed by transfecting the pCPSA plasmids into COS cells. The control untransfected cells (a) and PSA-transfected cells (b) were stained with $\alpha$-PSA antibodies

immunization could also be achieved in rhesus macaques. We immunized four rhesus macaques (two male and two female) intramuscularly with $500 \mu \mathrm{g}$ of pCPSA DNA vaccine construct at weeks 0,4 , and 10 . The sera samples were collected at various time points and were assayed for the induction of PSA-specific IgG antibodies. We observed that DNA immunization can elicit PSA-specific antibody responses in two of four animals $(50 \%)$ (Figure 2a). The PSA-specific humoral response was detected in the vaccinated macaques as early as 6 weeks post-immunization and remained persistent in these responders for at least 14 weeks. It is interesting to note that $50 \%$ of female macaques, which do not produce PSA, responded positively to pCPSA vaccination. It is also interesting that the same percentage of male macaques (which already produce their own macaque PSA) displayed PSA-specific humoral responses. Moreover, a booster effect was observed in both responders after the third injection at week 10 .

Furthermore, these antigen-reactive sera from the immunized monkeys were PSA-positive by Western blot analysis. As shown in Figure 2b, the sera collected from monkeys (MK1 and MK4) at 20 weeks postimmunization were analysed by Western blot analysis. The sera of control monkeys did not show reactivity. 


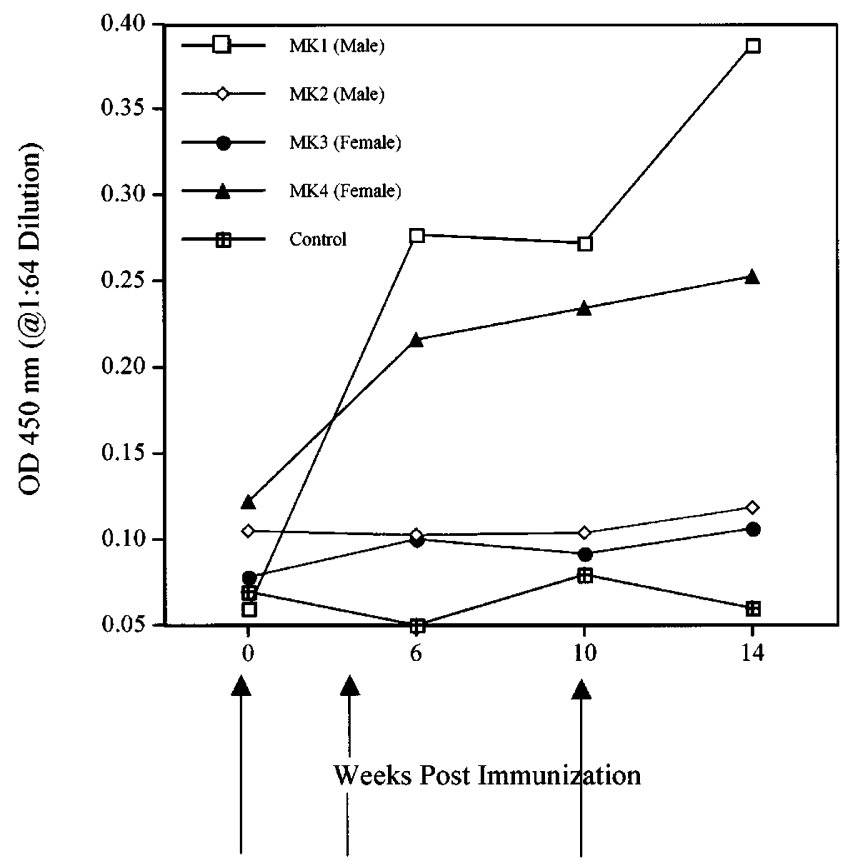

Immunzation $\mathrm{w} / 500 \mu \mathrm{g}$ of pCPSA

Figure 2 Induction of PSA-specific antibody responses in rhesus macaques. (a) Four rhesus macaques (two male and two female) were immunized intramuscularly with $500 \mu \mathrm{g}$ of pCPSA DNA vaccine construct at weeks 0,4 , and 10 (as indicated by the arrows). One control animal was injected with control vector pCDNA3 with identical regimen. The sera samples were collected and were assayed for the induction of PSA-specific antibodies. At 1:128 dilution, PSA-specific antibody response was detected as early as week 6 in 50\% of pCPSA immunized animals. The antigen-specific antibody response remained persistent in these responders. (b) Induction of PSA-specific Western reactivity in immunized macaques. The sera collected from monkeys MK1 (lane 1) and MK4 (lane 2) at 20 weeks post-immunization were analysed by Western bot analysis against recombinant PSA protein. The PSA band at the molecular weight of $30 \mathrm{kD}$ is indicated by the arrow. The sera from the control macaque (lane 3) was negative, while both positive control lanes, the monoclonal PSA Ab (lane 4) and the Rabbit polyclonal anti-PSA Ab (lane 5), were positive

In contrast, the sera collected from animals immunized with pCPSA showed distinct PSA band at the molecular weight of $30 \mathrm{kD}$. This finding illustrates the strength of the humoral response in these animals.

\section{DNA immunization induces PSA-specific cellular responses in rhesus macaques}

The effect of DNA immunization on antigen-specific lymphoproliferative responses was examined in macaques immunized as described above. As shown on Figure 3, we observed positive PSA-specific lymphoproliferative (LPA) responses in three out of four animals $(\mathrm{SI}>2)$, and significant LPA responses $(\mathrm{SI}>4)$ were induced in $50 \%$ of animals. It was interesting to note that macaques MK2 and MK3 displayed higher levels of lymphoproliferative response while MK1 and MK4 had higher levels of humoral response. Additional studies with more macaques would be needed to determine the significance of such immune response polarity.

Given these immune responses following the DNA immunization in macaques, the effects of increase in vaccine dosage and frequency of administration on the induction of PSA-specific LPA responses were investigated. Two additional rhesus macaques (MK5 and MK6) were immunized intramuscularly with $1 \mathrm{mg}$ of pCPSA DNA vaccine construct at weeks $0,4,10$ and 14 (4 mg total doses). One control animal was injected with control vector pCDNA3 with identical regimen. Induction of PSA-specific LPA responses were analysed in these animals. As shown in Figure 4, four immunizations with $1 \mathrm{mg}$ vaccine dosage resulted in a significant induction of PSA-specific LPA responses in the PSA vaccine immunized macaques (MK5 and MK6). These results demonstrate that more frequent immunizations with a higher dose of vaccine can significantly enhance the level of LPA responses. In addition, a booster effect was observed following the fourth injections.

Cytokines play a key role in directing and targeting immune cells during the development of the immune response. For instance, IFN- $\gamma$ is produced by Th1 and $\mathrm{CD}^{+} \mathrm{T}$ cells and is intricately involved in the regulation or development of anti-viral $\mathrm{T}$ cell-mediated immune responses (Clerici et al., 1993; Rosenberg et 


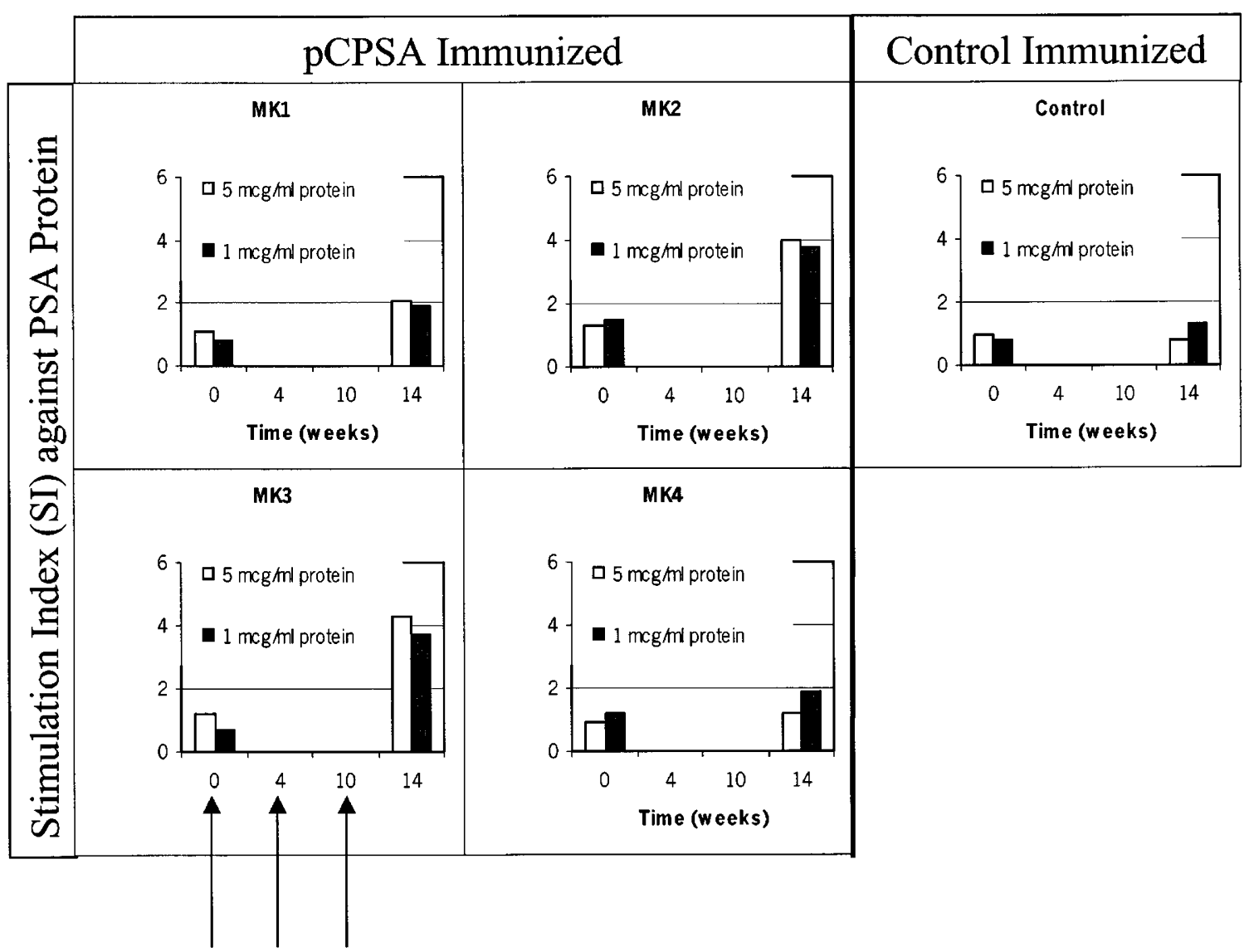

Immunzation $\mathrm{w} / 500 \mu \mathrm{g}$ of $\mathrm{pCPSA}$

Figure 3 Induction of PSA-specific lymphoproliferative responses in rhesus macaques. Induction of lymphoproliferative responses against PSA proteins were examined in animals immunized as described in Figure 2. PSA-specific lymphoproliferative responses were observed in three out of four animals $(\mathrm{SI}>2)$, and $50 \%$ of animals displayed significant lymphoproliferative responses $(\mathrm{SI}>4)$

al., 1997). In contrast, IL-4 plays a dominant role in B cell-mediated immune responses (Seder and Paul, 1994). Thus, analysis of these cytokines secreted by stimulated $\mathrm{T}$ cells may be important in elucidating the extent of cell-mediated responses following immunization (Lekutis et al., 1997). As shown in Figure 5, the stimulated $\mathrm{T}$ cells from the PSA-immunized rhesus macaques (MK5 and MK6) produced higher levels of IFN- $\gamma$ than the control vector immunized animals. On the other hand, the level of IL-4 produced by either group was similar. These results support that the responses in immunized macaques displayed a strong Th1 phenotype with potent induction of IFN- $\gamma$. Th1 phenotypes are a hallmark of this vaccine approach in mice (Kim et al., 1998a) and in humans (Boyer et al., 1999).

\section{Physical consequences of immunization}

Since the ultimate goal of vaccine or therapeutic strategies requires understanding of the consequences of a particular immunization strategy, the effects of PSA vaccine were examined in these primates. The macaques were tested for complete blood counts, leukocyte differentials and hepatic and renal chemistries. As shown in Table 1, the complete blood counts remained within the normal limits throughout the observation periods. In addition, hepatic and renal functional measurements did not indicate any adverse reaction to immunization (Table 2). We also examined the vaccine injection sites at specific times following immunization and did not observe any significant irritation on the vaccination site (data not shown). These results are consistent with the safety observation we had previously made in humans receiving vaccination with DNA constructs encoding for HIV-1 antigens (MacGregor et al., 1998).

We also examined the effect of immunization on the prostate of the immunized animals (males only) 24 weeks post-last immunization. We prepared frozen section slides of the prostate tissue received and stained them with hematoxylin and eosin (H\&E) stain. As shown in Figure 6, we observed some evidence of infiltrating cells in the prostate tissue, while suggesting a direct link between this infiltration and the vaccine protocol will require more study. Overall, it is 


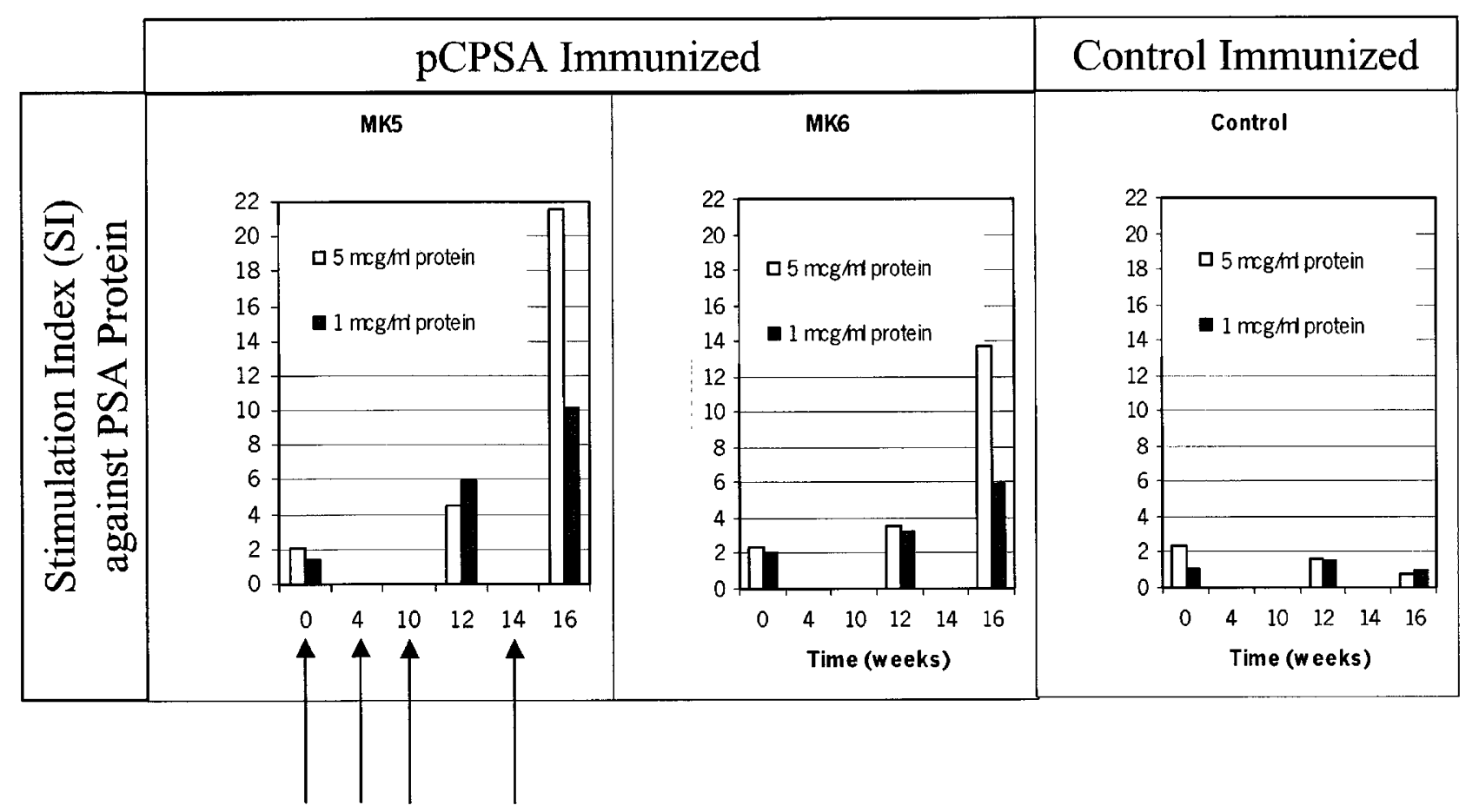

Immunzation w/ $1 \mathrm{mg}$ of pCPSA

Figure 4 Induction of PSA-specific lymphoproliferative responses in rhesus macaques. Two rhesus macaques (MK5 and MK6) were immunized intramuscularly with $1 \mathrm{mg}$ of pCPSA DNA vaccine construct at weeks $0,4,10$ and 14 (as indicated by the arrows). One control animal was injected with control vector pCDNA3 with identical regimen. Induction of PSA-specific lymphoproliferative responses were analysed in these animals

interesting to note that no adverse symptoms were noted during the routine and clinical examinations of these macaques throughout the study period (Tables 1 and 2). The clinical significance of the prostate tissue infiltration observed here is currently not clear.

\section{Discussion}

Immune-based therapies are promising strategies to treat cancer. Several immunotherapeutics against cancer have already been investigated (Small, 1999; Tuting et al., 1997). Examples include the injection of live, irradiated, and autologous tumor cells transfected with cytokines (Sandra, 1994; Vieweg et al., 1994). In addition, a recombinant vaccinia virus engineered to express tumor specific antigens and autologous dendritic cells loaded with peptide sequences of cancer antigens have been investigated as possible vaccines (Hodge et al., 1995; Lotze et al., 1997; Malkowicz and Johnson, 1998; Murphy et al., 1996; Porgador et al., 1996; Tjoa et al., 1996).

DNA vaccination is an important candidate for potential immunotherapy against cancer. Extensive experiments have shown that the DNA vaccines' ability to elicit humoral and cellular responses in vivo in a safe and well-tolerated manner in various model systems, including rodents and non-human primates, is now being explored in humans. The first DNA vaccine studies to enter the clinic were DNA vaccines encoding for HIV-1 MN envelope (MacGregor et al., 1998). Fifteen healthy HIV-1 sero-positive volunteers in the trial received three injections each separated by 10 weeks with escalating dosage (three dosage groups of five subjects) of envelope vaccine. Preliminary results reveal no significant clinical or laboratory adverse effects measured in all three dosage groups (30, 100, $300 \mu \mathrm{g}$ ). More importantly, the immunized individuals developed an increase in antibody responses to envelope proteins and peptides after receiving the $100 \mu \mathrm{g}$ dose. Some increases in cellular responses including the lymphoproliferative and CTL responses as well as $\beta$-chemokine expression were also observed (MacGregor et al., 1998). In addition, phase I trials evaluating a gag/pol construct as a therapeutic vaccine as well as a prophylactic DNA vaccine study for HIV has been undertaken. In another clinical study, the healthy volunteers who were immunized with DNA vaccines encoding for malaria proteins developed CTL responses against the target cells prepared with malaria peptides (Wang et al., 1998).

A major focus of developing DNA vaccines against cancer has been the use of tumor associated antigens. These are proteins produced by tumor cells, which can be presented on the cell surface in the context of major histocompatibility complexes (Kelley and Cole, 1998). 
Recently, the antigens such as the carcinoembryonic antigen (CEA) and PSA have been the targets of immunotherapy of cancer. DNA vaccine encoding for human CEA was characterized in a murine model, and

A)

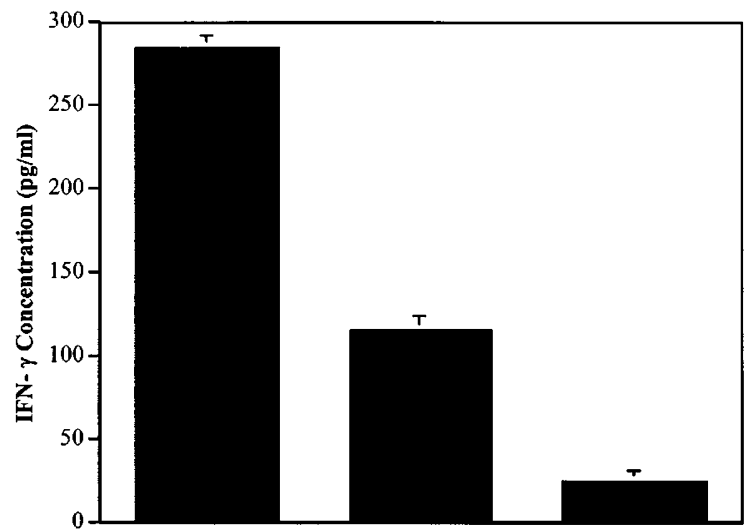

B)

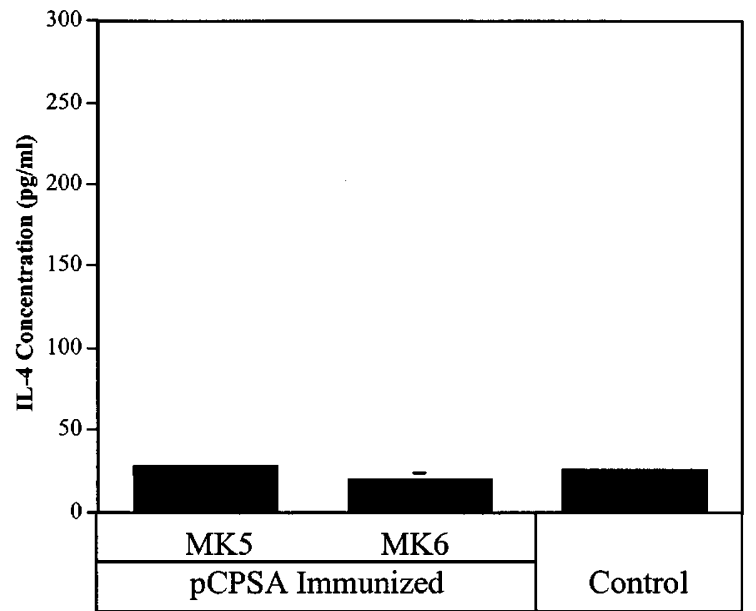

Figure 5 Expression of cytokines by stimulated T cells. Supernatants from PSA-specific lymphoproliferative assay described in Figure 3 were collected and tested for cytokine profile using ELISA kits for IFN- $\gamma$ (a) and IL-4 (b)
CEA specific humoral and cellular responses were detected in the immunized mice (Conry et al., 1994). The CEA DNA vaccine was also characterized in a canine model, where sera obtained from dogs injected intramuscularly with the construct demonstrated an increase in antibody levels (Smith et al., 1998). The CEA DNA vaccine was also examined in the pig-tail macaques, and this strategy is currently being investigated in humans (Conry et al., 1998).

We have previously reported on the use of DNA vaccine which encodes for human PSA to induce strong and persistent antibody responses against PSA for at least 180 days following immunization (Kim et al., 1998b). In addition, significant $\mathrm{CD}^{+}{ }^{+} \mathrm{T}$ helper cell as well as $\mathrm{CD} 88^{+} \mathrm{CTL}$ responses were observed. These results demonstrate the potential utility of targeting PSA as a testable immunotherapy against prostate cancer.

In another study, recombinant vaccinia virus vaccines expressing human PSA (rV-PSA) were studied in rodent as well as in non-human primate models (Hodge et al., 1995). Hodge et al. (1995) investigated the immunological effects of a recombinant vaccinia virus expressing human PSA (rV-PSA) in rhesus macaques and observed that the rhesus monkeys exhibited little vaccine toxicity other than the lowgrade fever expected with vaccinia infection. In addition, the macaques receiving the high dose rVPSA vaccination exhibited cellular immune responses specific to PSA. This vaccinia virus-based PSA vaccine has also been tested in Phase I trial (Eder et al., 2001).

In this report, we extend this strategy to investigate for immunology and safety in macaques. Because of the high degree of similarity between the rhesus and human prostate gland and PSA (94\%), this animal model was well suited to accurately assess the effects of PSA vaccine. We immunized four rhesus macaques (two male and two female) intramuscularly with $500 \mu \mathrm{g}$ of pCPSA DNA vaccine construct at weeks 0,4 , and 10. The PSA-specific IgG response was detected in the vaccinated macaques as early as 6 weeks postimmunization and remained persistent in these responders $(50 \%)$ through later time points. It is of interest

Table 1 Summary of effects on rhesus macaques

\begin{tabular}{|c|c|c|c|c|c|c|c|}
\hline & \multicolumn{3}{|c|}{ PSA-immunized $(\mathrm{n}=4)$} & \multicolumn{3}{|c|}{ Control-immunized $(\mathrm{n}=3)$} & \multirow{2}{*}{$\begin{array}{c}\text { Normal } \\
\text { range }\end{array}$} \\
\hline & Week 10 & Week 14 & Week 34 & Week 10 & Week 14 & Week 34 & \\
\hline $\mathrm{WBC}\left(\times 10^{3}\right)$ & $6.1( \pm 1.5)$ & $6.6( \pm 3.1)$ & $6.5( \pm 2.0)$ & $6.5( \pm 0.7)$ & $5.6( \pm 1.7)$ & $8.7( \pm 1.8)$ & $(1.4-7.6)$ \\
\hline $\operatorname{RBC}\left(\times 10^{6}\right)$ & $5.4( \pm 0.2)$ & $5.4( \pm 0.3)$ & $5.6( \pm 0.2)$ & $5.4( \pm 0.1)$ & $5.5( \pm 0.2)$ & $5.6( \pm 0.2)$ & $(4.5-6.9)$ \\
\hline HGB (gm/dl) & $12.7( \pm 0.7)$ & $12.7( \pm 0.5)$ & $13.2( \pm 0.5)$ & $12.0( \pm 0.4)$ & $12.2( \pm 0.5)$ & $12.5( \pm 0.5)$ & $(10.6-15.6)$ \\
\hline HCT $(\%)$ & $39.1( \pm 2.1)$ & $39.2( \pm 1.0)$ & $40.6( \pm 1.1)$ & $27.9( \pm 18.8)$ & $39.0( \pm 1.4)$ & $39.6( \pm 1.5)$ & $(35.0-48.2)$ \\
\hline MCV (fl) & $73( \pm 3.7)$ & $73.5( \pm 3.7)$ & $73.0( \pm 3.7)$ & $71.7( \pm 0.6)$ & $71.3( \pm 0.6)$ & $71.3( \pm 0.6)$ & $(66.0-80.2)$ \\
\hline $\mathrm{MCH}(\mathrm{pg})$ & $23.7( \pm 1.1)$ & $23.7( \pm 1.4)$ & $23.6( \pm 1.1)$ & $22.4( \pm 0.3)$ & $22.3( \pm 0.2)$ & $22.4( \pm 0.1)$ & $(21.0-25.0)$ \\
\hline $\mathrm{MCHC}(\mathrm{g} / \mathrm{dl})$ & $32.5( \pm 0.5)$ & $32.3( \pm 0.4)$ & $32.5( \pm 1.3)$ & $31.3( \pm 0.5)$ & $31.2( \pm 0.4)$ & $31.5( \pm 0.2)$ & $(29.2-33.8)$ \\
\hline Poly $(\%)$ & $55.5( \pm 13.6)$ & $57.0( \pm 18.7)$ & $48.5( \pm 13.5)$ & $45.3( \pm 9.0)$ & $50.7( \pm 13.1)$ & $53.7( \pm 11.6)$ & $(14.2-87.8)$ \\
\hline Abs Poly & $3.5( \pm 1.5)$ & $4.0( \pm 3.0)$ & $3.0( \pm 0.9)$ & $2.9( \pm 0.7)$ & $3.0( \pm 1.5)$ & $4.6( \pm 0.9)$ & $(0-12.4)$ \\
\hline Lymph (\%) & $42.5( \pm 14.3)$ & $41.3( \pm 18.2)$ & $48.3( \pm 16.2)$ & $54.0( \pm 8.7)$ & $49.0( \pm 13.5)$ & $46.0( \pm 12.1)$ & $(11.0-83.0)$ \\
\hline Abs Lymph & $2.5( \pm 0.7)$ & $2.4( \pm 1.3)$ & $3.3( \pm 1.7)$ & $3.5( \pm 0.6)$ & $2.6( \pm 0.1)$ & $4.1( \pm 1.6)$ & $(0.2-8.1)$ \\
\hline PLT $\left(\times 10^{3}\right)$ & $366.0( \pm 115.2)$ & $396.3( \pm 108.0)$ & $380.0( \pm 79.4)$ & $378.3( \pm 32.5)$ & $381.0( \pm 48.5)$ & $346.3( \pm 31.1)$ & $(181.8-661.8)$ \\
\hline
\end{tabular}

Total leukocyte count (WBC); Erythrocyte count (RBC); Hemoglobin concentration (HGB); Hematocrit value (HCT); Mean corpuscular volume (MCV); Mean corpuscular hemoglobin (MCH); Mean corpuscular hemoglobin concentration (MCHC); Platelet count (PLT) 
Table 2 Serum chemistry summary

\begin{tabular}{|c|c|c|c|c|c|}
\hline & \multicolumn{2}{|c|}{ PSA-immunized $(\mathrm{n}=3)$} & \multicolumn{2}{|c|}{ Control-immunized $(\mathrm{n}=3)$} & \multirow[b]{2}{*}{ Normal range } \\
\hline & Week 39 & Week 41 & Week 39 & Week 41 & \\
\hline Glucose (mg/dl) & $59.0( \pm 6.2)$ & $59.3( \pm 4.6)$ & $63.3( \pm 2.3)$ & $56.7( \pm 6.4)$ & $(28.1-123.2)$ \\
\hline BUN (mg/dl) & $19.0( \pm 1.0)$ & $187( \pm 0.6)$ & $20.7( \pm 3.1)$ & $19.0( \pm 2.6)$ & $(10.4-28.9)$ \\
\hline Creatinine $(\mathrm{mg} / \mathrm{dl})$ & $1.0( \pm 0.2)$ & $0.9( \pm 0.1)$ & $0.8( \pm 0.0)$ & $0.8( \pm 0.0)$ & $(0.6-1.4)$ \\
\hline Total protein $(\mathrm{g} / \mathrm{dl})$ & $7.6( \pm 0.5)$ & $7.4( \pm 0.4)$ & $7.0( \pm 0.2)$ & $6.8( \pm 0.2)$ & $(6.7-8.4)$ \\
\hline Albumin $(\mathrm{g} / \mathrm{dl})$ & $4.4( \pm 0.4)$ & $4.3( \pm 0.3)$ & $4.3( \pm 0.3)$ & $4.2( \pm 0.3)$ & $(3.1-5.4)$ \\
\hline Globulin (g/dl) & $3.1( \pm 0.4)$ & $3.1( \pm 0.6)$ & $2.7( \pm 0.2)$ & $2.6( \pm 0.2)$ & $(2.0-4.4)$ \\
\hline $\mathrm{A} / \mathrm{G}$ ratio & $1.4( \pm 0.2)$ & $1.4( \pm 0.3)$ & $1.6( \pm 0.2)$ & $1.6( \pm 0.2)$ & $(0.7-2.0)$ \\
\hline Calcium (mg/dl) & $9.5( \pm 0.6)$ & $9.2( \pm 0.5)$ & $9.4( \pm 0.3)$ & $9.3( \pm 0.2)$ & $(8.8-10.7)$ \\
\hline Phosphorus (mg/dl) & $5.3( \pm 1.2)$ & $5.5( \pm 1.2)$ & $6.2( \pm 0.9)$ & $6.9( \pm 0.5)$ & $(4.3-7.9)$ \\
\hline Total bilirubin $(\mathrm{mg} / \mathrm{dl})$ & $0.1( \pm 0.1)$ & $0.2( \pm 0.1)$ & $0.1( \pm 0.0)$ & $0.2( \pm 0.1)$ & $(0.0-0.6)$ \\
\hline $\operatorname{ALKP}(\mathrm{u} / \mathrm{l})$ & $315.0( \pm 281.4)$ & $307.3( \pm 264.2)$ & $675.0( \pm 151.6)$ & $715.0( \pm 164.9)$ & $(120.5-1053.5)$ \\
\hline $\operatorname{ALT}(\mathrm{u} / \mathrm{l})$ & $54.0( \pm 33.6)$ & $41.0( \pm 28.2)$ & $26.3( \pm 7.5)$ & $23.2( \pm 4.2)$ & $(4.8-75.7)$ \\
\hline $\operatorname{AST}(\mathrm{u} / \mathrm{l})$ & $44.7( \pm 11.7)$ & $39.3( \pm 11.6)$ & $30.7( \pm 4.7)$ & $33.0( \pm 6.1)$ & $(7.4-91.7)$ \\
\hline Sodium (mEq/l) & $143.0( \pm 1.7)$ & $145.0( \pm 1.7)$ & $145.0( \pm 1.0)$ & $145.0( \pm 1.0)$ & $(143.3-152.9)$ \\
\hline Potassium (mEq/l) & $3.6( \pm 0.5)$ & $3.4( \pm 0.2)$ & $3.2( \pm 0.3)$ & $3.4( \pm 0.1)$ & $(2.9-5.6)$ \\
\hline Chloride (mEq/l) & $106.7( \pm 0.6)$ & $108.3( \pm 0.6)$ & $106.7( \pm 2.5)$ & $108.7( \pm 2.5)$ & $(102.6-113.3)$ \\
\hline Triglycerides (mg/dl) & $44.0( \pm 11.3)$ & $39.7( \pm 13.0)$ & $54.7( \pm 7.6)$ & $46.0( \pm 6.0)$ & $(0.0-126.4)$ \\
\hline Cholesterol (mg/dl) & $147.3( \pm 13.9)$ & $144.3( \pm 15.5)$ & $158( \pm 11.4)$ & $148.7( \pm 8.5)$ & $(91.5-212.3)$ \\
\hline GGT $(\mathrm{u} / \mathrm{l})$ & $82.0( \pm 4.4)$ & $80.7( \pm 6.4)$ & $82.7( \pm 13.1)$ & $87.7( \pm 19.0)$ & $(24.4-108.9)$ \\
\hline
\end{tabular}

Blood urea nitrogen (BUN); Alkaline phosphatase (ALKP); Alanine aminotransferase (ALT); Aspartate aminotransferase (AST)
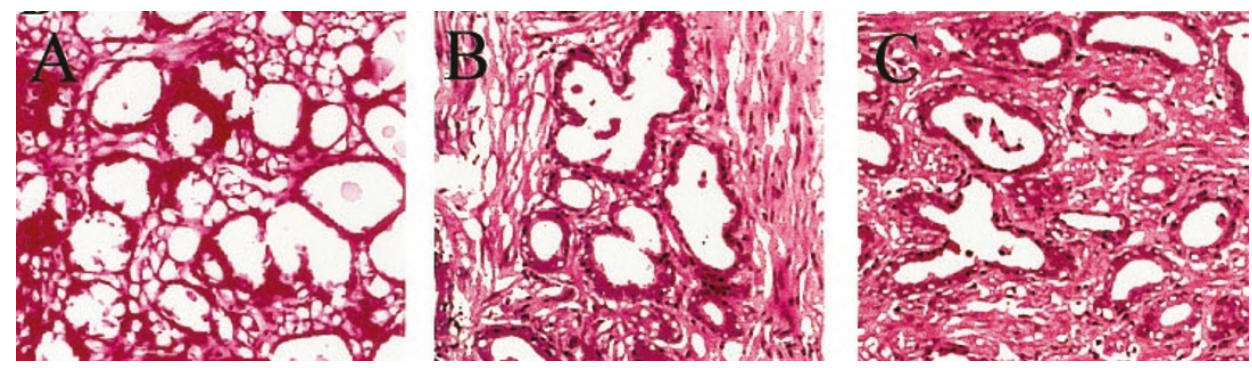

Figure 6 Immunohistochemical analysis of prostate tissues collected from immunized macaques. At week 34, frozen section slides were prepared from the prostate tissues from pCPSA immunized macaques (a and b) and control macaque (c) were stained with hematoxylin and eosin $(\mathrm{H} \& \mathrm{E})$ stain

that the frequency and the degree of PSA-specific IgG responses induced from DNA immunization were more potent than those induced from the high dose administration of rV-PSA in rhesus macaques (Hodge et al., 1995).

Furthermore, we observed positive PSA-specific LPA responses in three out of four animals. The potency of PSA-specific LPA responses induced from DNA immunization was similar to that from the high dose administration of rV-PSA in rhesus macaques (Hodge et al., 1995). The positive immune response rate may be dose-dependent since two additional rhesus macaques (MK5 and MK6) immunized with a higher $1 \mathrm{mg}$ dose of pCPSA DNA vaccine construct at weeks 0,4 , 10 and 14 resulted in $100 \%$ positive immune response rate. In addition, more frequent immunization with higher dose of vaccine seemed to enhance the level of LPA responses, and a booster effect was observed following the third and fourth injections. Moreover, we observed that the stimulated $\mathrm{T}$ cells from the PSAimmunized rhesus macaques produced higher levels of Th1 type cytokine IFN- $\gamma$ than the control vector immunized animals.
While the pCPSA immunizations induced humoral and cellular immune responses, the injections did not result in specific adverse effects in the immunized macaques, as indicated by complete blood counts, leukocyte differentials and hepatic and renal chemistries. The macaques appeared healthy, without any physical signs of toxicity throughout the observation period. In addition, we did not observe any adverse effect on the vaccination site from the immunization (data not shown). We did observe some evidence of infiltrating cells in the prostate tissue almost 6 months from the last immunization. Further studies are needed to elucidate the clinical significance of the prostate tissue infiltration.

These safety observations are consistent with the results observed in humans receiving vaccination with DNA constructs encoding for HIV-1 antigens (MacGregor et al., 1998). Overall the vaccine recipients received the vaccines in a well tolerated manner, with no significant clinical or laboratory adverse effects measured in all dosage groups $(30,100,300 \mu \mathrm{g}$ per dose). In addition, these observations are similar to the results observed in a study on the immunization of 
recombinant vaccinia virus vaccines expressing human PSA in rhesus macaques (Hodge et al., 1995). Hodge et al. (1995) reported that PSA-vaccinia immunized rhesus macaques exhibited little vaccine toxicity other than the low-grade fever expected with wild-type control vaccinia infection.

This study utilizes a relevant pre-clinical model to evaluate the pCPSA vaccine immunogenecity and safety and extends the immunogenecity findings observed from the rodent studies. Due to $94 \%$ similarity between the rhesus macaques and human PSA protein, the rhesus macaque model was well suited to assess the effects of PSA vaccine. We observed that the immunization of rhesus macaques with pCPSA vaccine induced potent humoral cellular immune responses without any measurable adverse effects. The apparent safety and immunogenecity of the vaccine, especially the induction of potent cellular immune responses support the potential utility of this vaccine strategy. Because human and rhesus PSA do not share $100 \%$ homology, the ultimate test of this strategy rests with appropriate studies in the clinic.

\section{Materials and methods}

\section{Construction and expression of pCPSA DNA constructs}

DNA vaccine cassettes expressing PSA were constructed by cloning the complete coding sequence of PSA into clinical expression vector under the control of CMV promoter. The expression of PSA by the pCPSA plasmids was assayed by transfecting them into COS cells using the calcium phosphate transfection method. Briefly, monkey COS cells line cells $\left(1 \times 10^{6}\right)$ grown in DMEM $($ Gibco-BRL, Grand Island, NY, USA) supplemented with $10 \%$ FBS, $100 \mathrm{U} / \mathrm{ml}$ penicillin and $100 \mu \mathrm{g} / \mathrm{ml}$ streptomycin were plated on $60 \mathrm{~mm}$ plates for $24 \mathrm{~h}$ prior to being transfected with $10 \mu \mathrm{g}$ of pCPSA plasmid DNA. The cells were harvested at 5 days post-transfection and were washed twice with PBS (Gibco-BRL) and fixed with $4 \%$ paraformaldehyde solution. These fixed cell suspensions were dropped onto a slide and air-dried for at least $2 \mathrm{~h}$. The cells were dehydrated by immersing the slides in solutions of $50,70,90$, then $98 \%$ of $\mathrm{EtOH}$ for $3 \mathrm{~min}$ in each solution, and then air-dried again for $20 \mathrm{~min}$. The cells were blocked with $3 \%$ goat serum (Gibco-BRL) in PBS for $20 \mathrm{~min}$, and then incubated with $1: 250$ dilution of rabbit anti-PSA primary antibody (Fitzgerald Industries International, Inc. Concord, MA, USA) for $1 \mathrm{~h}$ at room temperature. After washing with PBS for $5 \mathrm{~min}$, the cells were incubated with biotinylated anti-rabbit IgG (Sigma Chemical Co, St. Louis, MO, USA) in a 1:500 dilution for $45 \mathrm{~min}$ at room temperature. After washing, the slides were incubated with Avidine and then Biotinylated Alkaline Phosphatase in 1:500 dilutions for $30 \mathrm{~min}$ each, and the color was developed by adding substrate nitro-blue tetrazolium (NBT)/5-bromo-4-chloro-3-indolyl-phosphate (BCIP). The slides were viewed with a Nikon OPTIPHOT fluorescing microscope (Nikon Inc., Tokyo, Japan) using a $200 \times$ objective (Nikon Fluo 40X Ph3D2). Slide photographs were obtained using a Nikon camera FX35DX with exposure control by Nikon UFX-II and Kodak Ektachrome 160T slide film.

\section{DNA inoculation of animals}

Rhesus macaques (Macaca mulatta) were individually housed at the Primedica Mason Labs (Worcester, MA, USA). All animal care and use procedures conformed to the revised Public Health Service Policy on Humane Care and Use of Laboratory Animals. Animals were anesthetized with ketamine HCL for all technical procedures. Macaques were immunized intramuscularly (IM) in the quadriceps with DNA preparations formulated in PBS and $0.25 \%$ bupivacaine- $\mathrm{HCl}$ on multiple occasions.

\section{ELISA}

Serum antibody reactivity purified PSA protein was analysed by ELISA as previously described (Boyer et al., 1997). Briefly, recombinant PSA protein (Fitzgerald Industries) was resuspended in PBS to a concentration of $0.5 \mu \mathrm{g} / \mathrm{ml}$. Fifty $\mu \mathrm{l}$ $(25 \mathrm{ng})$ of each protein preparation was incubated in each of the ELISA wells overnight at $4{ }^{\circ} \mathrm{C}$. Plates were then rinsed with washing buffer $(0.45 \% \mathrm{NaCl}$ in deionized water containing $0.05 \%$ Tween-20) and blocked with blocking buffer $(5 \%$ non-fat dry milk in PBS with $1 \%$ BSA and $0.05 \%$ Tween-20) for $2 \mathrm{~h}$ at $37^{\circ} \mathrm{C}$. Serum samples were then diluted in dilution buffer $(5 \%$ non-fat dry milk in PBS with $0.05 \%$ Tween-20) at the appropriate dilutions and incubated in duplicate or triplicate in recombinant protein coated wells for $1 \mathrm{~h}$ at $37^{\circ} \mathrm{C}$, washed and then incubated for $1 \mathrm{~h}$ at $37^{\circ} \mathrm{C}$ with a goat anti-human Ig-horseradish peroxidase conjugate (Sigma Chemical Co) diluted in dilution buffer at the concentration suggested by the manufacturer. After extensive washing the plates were developed with $3,3^{\prime}, 5,5^{\prime}$-tetramethylbenzidine dihydrochloride (TMB) substrate $(100 \mu \mathrm{g} / \mathrm{ml})$, the reaction was stopped with $2 \mathrm{~N} \mathrm{H}_{2} \mathrm{SO}_{4}$ and color development was quantitated at $450 \mathrm{~nm}$. BSA coated wells were used as negative binding control wells in these assays. Specific binding (absorbance at $450 \mathrm{~nm}$ ) was calculated by subtracting $\mathrm{A}_{450}$ values from sera samples bound to BSA (that is, control) from $\mathrm{A}_{450}$ values from sera samples bound to gp120; that is, experimental wells $\left(\mathrm{A}_{450}\right.$ experimental $-\mathrm{A}_{450}$ control).

\section{Western blot analysis}

Three $\mu \mathrm{g}$ of PSA protein was resolved on a $10 \%$ SDSPAGE prep gel and the protein was transferred to PVDF Immobilon ${ }_{-} \mathrm{P}$ membrane (Millipore, Bedford, MA, USA). The membrane was cut into strips and each strip was incubated with PSA immunized monkey sera, mouse monoclonal PSA Ab-3 (ER-PR8 + A67-B/E3) (NeoMarkers Inc., Union City, CA, USA), or rabbit anti-PSA primary $A b$ in $1: 250$ dilution. After incubation with HRP conjugated secondary Abs, the presence of Abs was confirmed by light emitting non-radioactive reagent ECLTM Western blotting (Amersham Pharmacia Biotech Inc., Piscataway, NJ, USA).

\section{Lymphoproliferative assay}

Peripheral blood lymphocytes were prepared as previously described (Boyer, 1997). The isolated cell suspensions were resuspended to a concentration of $5 \times 10^{5}$ cells $/ \mathrm{ml}$ in a media consisting of RPMI 1640 (Gibco-BRL) with $10 \%$ fetal calf serum (Gibco-BRL). A $100 \mu \mathrm{l}$ aliquot containing $5 \times 10^{5}$ cells was immediately added to each well of a 96-well microtiter round bottom plate. Recombinant PSA protein (Fitzgerald Industries) at the final concentrations of 5 and $1 \mu \mathrm{g} / \mathrm{ml}$ were added to wells in triplicate. The cells were incubated at $37^{\circ} \mathrm{C}$ in $5 \% \mathrm{CO}_{2}$ for 3 days. One $\mu \mathrm{Ci}$ of tritiated 
thymidine was added to each well and the cells were incubated for $12-18 \mathrm{~h}$ at $37^{\circ} \mathrm{C}$. The plates were harvested and the amount of incorporated tritiated thymidine was measured in a Beta Plate reader (Wallac, Turku, Finland). Stimulation Index was determined from the formula:

Stimulation Index $(\mathrm{SI})=($ experimental count/spontaneous count $)$

Spontaneous count wells (media only) include $10 \%$ fetal calf serum. To assure that cells were healthy, Concanavalin A (Sigma) was used as a polyclonal stimulator positive control. The data was analysed statistically using a paired Student $t$-test.

\section{Cytokine expression analysis}

Supernatants from PSA-specific lymphoproliferative assay were collected and tested for cytokine profile using ELISA kits for IFN- $\gamma$ (Figure 5a) and IL-4 (Figure 5b) (Biosource International Inc., Camarillo, CA, USA). For each sample at each time point, $100 \mu \mathrm{l}$ of supernatant were tested in triplicate wells. Each well value was used to derive the average and the standard deviation values. The $P$ values were calculated using the Student $t$-test.

\section{References}

Armbruster DA. (1993). Clin. Chem., 39, 181-195.

Boring CC, Squires TS and Tong T. (1994). Ca: Cancer J. Clin., 44, 7-26.

Boyer JD, Ugen KE, Wang B, Agadjanyan MG, Gilbert L, Bagarazzi M, Chattergoon M, Frost P, Javadian A, Williams WV, Refaeli Y, Ciccarelli RB, McCallus D, Coney L and Weiner DB. (1997). Nature Med., 3, 526532.

Boyer JD, Chattergoon MA, Ugen KE, Shaw A, Bennett M, Cohen A, Nyland S, Lacy K, Bagarazzi ML, Higgins TJ, Baine Y, Ciccarelli RB, Ginsberg RS, MacGregor RR and Weiner DB. (1999). Clin. Immunol., 90, 100-107.

Clerici M, Lucey DR, Berzofsky JA, Pinto LA, Wynn TA, Blatt SP, Dolan MJ, Hendrix CW, Wolf SF and Shearer GM. (1993). Science, 262, $1721-1724$.

Conry RM, LoBuglio AF, Kantor J, Schlom J, Loechel F, Moore SE, Sumerel LA, Barlow DL, Abrams S and Curiel DT. (1994). Cancer Res., 54, 1164-1168.

Conry RM, White SA, Fultz PN, Khazaeli MB, Stron TV, Allen KO, Barlow DL, Moore SE, Coan PN, Davis I, Curiel DT and LoBuglio AF. (1998). Clin. Cancer Res., 4, 2903-2912.

D'Amico AV, Whittington R, Kaplan I, Beard C, Schultz D, Malkowicz SB, Wein A, Tomaszewski JE and Coleman CN. (1998). Cancer, 82, 334-341.

Eder JP, Kantoff PW, Roper K, Xu GX, Bubley GJ, Boyden J, Gritz L, Mazzara G, Oh WK, Arlen P, Tsang KY, Panicali D, Schlom J and Kufe DW. (2001). Clin. Cancer Res., 6, $1632-1638$.

Garnick MB and Fair WR. (1998). Sci. Am., 274, 74-83.

Godley PA. (1999). Cancer Detect. Prev., 23, 316-324.

Hodge JW, Schlom J, Donohue SJ, Tomaszewski JE, Wheeler CW, Levine BS, Gritz L, Panicali S and Kantor JA. (1995). Int. J. Cancer, 63, 231-237.

Jiao S, Williams P, Berg RK, Hodgeman BA, Liu L, Repetto G and Wolff JA. (1992). Hum. Gene Ther., 3, 21-33.

Kelley JR and Cole DJ. (1998). Gene Ther. Mol. Biol., 2, $14-$ 30.
Immunohistochemical analysis of prostate from immunized macaques

Frozen section slides were prepared from the prostate tissues from pCPSA immunized macaques. Four micron frozen sections were made using a Leica 1800 cryostat (Leica Inc., Deerfield, IL, USA). To detect the presence of lymphocytes in muscle, the slides were stained with hematoxylin and eosin (H\&E) stain (Vector Labs). The slides were viewed with a Nikon OPTIPHOT fluorescing microscope (Nikon Inc., Tokyo, Japan) using a $40 \times$ objective (Nikon Fluo $40 \times$ Ph3D2). Slide photographs were obtained using a Nikon camera FX35DX with exposure control by Nikon UFX-II and Kodak Ektachrome 160T slide film.

\section{Acknowledgments}

This work was supported in part by grants from NIH to DB Weiner.

Kim JJ, Nottingham LK, Sin JI, Tsai A, Morrison L, Oh J, Dang K, Hu Y, Kazahaya K, Bennett M, Dentchev T, Wilson DM, Chalian AA, Boyer JD, Agadjanyan MG and Weiner DB. (1998a). J. Clin. Invest., 102, 1112-1124.

Kim JJ, Trivedi NN, Wilson DM, Mahalingam S, Morrison L, Tsai A, Chattergoon MA, Dang K, Patel M, Ahn L, Chalian AA, Boyer JD, Kieber-Emmons T, Agadjanyan MG and Weiner DB. (1998b). Oncogene, 17, 3125-3135.

Labrie F, DuPont A, Suburu R, Cusan L, Tremblay M, Gomez JL and Edmond J. (1992). J. Urol., 151, 1283 1290.

Lekutis C, Shiver JW, Liu MA and Letvin NL. (1997). $J$. Immunol., 158, $4471-4477$.

Letvin NL, Montefiori DC, Yasutomi Y, Perry HC, Davies M-E, Lekutis C, Alroy M, Freed DC, Lord CI, Handt LK, Liu MA and Shiver JW. (1997). Proc. Natl. Acad. Sci. USA, 94, 9378-9383.

Lotze MT, Shurin M, Davis I, Amoscato A and Storkus WJ. (1997). Adv. Exp. Med. Biol., 417, 551-569.

MacGregor RR, Boyer JD, Ugen KE, Lacy K, Gluckman S, Bagarazzi ML, Chattergoon M, Baine Y, Higgins TJ, Ciccarelli RB, Coney LR, Ginsberg RS and Weiner DB. (1998). J. Inf. Dis., 178, $92-100$.

Malkowicz SB and Johnson JO. (1998). Hematol. Oncol. Clin. North Am., 12, 649-664.

Murphy G, Tjoa B, Ragde H, Kenny G and Boynton A. (1996). Prostate, 29, 371-380.

O'Donnell PD and Finan BF. (1989). J. Urol., 142, $1227-$ 1229.

Porgador A, Snyder D and Gilboa E. (1996). J. Immunol., 156, 2918-2926.

Rosenberg ES, Billingsley JM, Caliendo AM, Boswell SL, Sax PE, Kalams SA and Walker BD. (1997). Science, 278, $1447-1450$.

Sandra MG. (1994). J. Urol., 151, 622-628.

Seder RA and Paul WE. (1994). Annu. Rev. Immunol., 12, $635-673$.

Small EJ. (1999). Curr. Opin. Oncol., 11, 226-235. 
Smith BF, Baker HJ, Curiel DT, Jiang W and Conry RM. (1998). Gene Ther., 5, 865-868.

Stenman UH, Leinonen J, Zhang WM and Finne P. (1999). Semin. Cancer Biol., 9, 83-93.

Tjoa B, Boynton A, Kenny G, Ragde H, Misrock SL and Murphy G. (1996). Prostate, 28, 65-69.

Tuting T, Storkus WJ and Lotze MT. (1997). J. Mol. Med., 75, $478-491$.

Vieweg J, Boczkowski D, Roberson KM, Edwards DW, Philip M, Philip R, Rudoll T, Smith C, Robertson C and Gilboa E. (1994). Cancer Res., 54, 1760-1765.
Wang MC, Kuriyama M, Papsidero LD, Loor RM, Valenzyela LA, Murphy GP and Chu TM. (1982). Methods Cancer Res., 19, 179-197.

Wang R, Doolan DL, Le TP, Hedstrom RC, Coonan KM, Charoenvit Y, Jones TR, Hobart P, Margalith M, Ng J, Weiss WR, Sedegah M, de Taisne C, Norman JA and Hoffman SL. (1998). Science, 282, 476-480.

Watt KWK, Lee P-J, M'Timkulu T, Chan W-P and Loor R. (1986). Proc. Natl. Acad. Sci. USA, 83, 3166-3170.

Zagars GK and Pollack A. (1995). Urology, 45, 476-483. 